\title{
Seismic Analysis and Optimization of a Rectangular Elevated Water Tank
}

\author{
Swathi C. Naik and M.S. Bhandiwad
}

\begin{abstract}
Water tanks play an important role in water supply networks, during and post-earthquake for vital reasons such as to extinguish fire, drinking purpose etc. In general there are three kinds of water tanks-tanks resting on ground, underground tanks and elevated tanks. Here we are studying only about the elevated rectangular tanks. This paper presents the seismic analysis of an elevated rectangular water tank with mid frame staging and is compared by changing the seismic zone as per IS: 1893-2002 (Part-2) and wind speeds for different soil conditions such as hard, medium and soft soil. The elevated rectangular tank has been modelled by using the software ETABS. The water tank is also optimized by $N$ Pandian method to give the optimum and economical design of water tank.
\end{abstract}

Keywords--- ETABS, $N$ Pandian Method, Rectangular Water Tank and Seismic Zones.

\section{INTRODUCTION}

$\mathrm{T}$ ANKS are used around the world for storing water, oils, inflammable liquids, chemicals etc. Water tanks, both elevated and ground level tanks play an important role in water supply networks during earthquakes and fire fighting. They should be in working condition during and post-earthquake for vital reasons such as to extinguish fire which occur due to earthquakes, drinking purpose etc.

The poor seismic performance of water tanks has been reported in the past few decades. Among the several reasons of failure in the past earthquakes, improper design of structural elements, low strength and ductility, effect of soil-structure interaction, etc have been highlighted in the past studies. Hence most of the studies are concentrated on the performance of elevated water tanks during earthquakes. Main objective of seismic design of structure is to ensure that the structure even though does not fully recent percent resist the earthquake force it at least has an acceptable performance when subjected to various intensity earthquakes and the probability of such occurrences during its lifetime.

\section{A. Classification of Tanks}

- Based on location

1. Ground level Tanks

2. Elevated Tanks

3. Underground Tanks

- Based on shape

Swathi C. Naik, PG Student, Civil Engineering, SDM College of Engineering, Dharwad, Karnataka, India. E-mail: swatinaik1824@gmail.com

M.S. Bhandiwad, Asst. Professor, Civil Engineering, SDM College of Engineering, Dharwad, Karnataka, India. E-mail:mallucv014@gmail.com DOI:10.9756/BIJMMI.8161
1. Circular Tanks

2. Rectangular Tanks

3. Intze Tanks

4. Conical Bottom Tanks

\section{B. Seismic Zoning}

Different locations have different geology. The possibility of occurrence of earthquakes and its damaging effects is different at different locations. Hence analysing the earthquakes in our country taking India as one whole region will not be precise. Thus India was divided into five regions known as Zones and a map representing these zones called

Seismic Zone Map is prepared to recognise these earthquake prone areas. India was divided into five zones - I, II, III, IV and V by the 1970 version of the zone map based on the levels of intensities sustained during past earthquakes. These maps need to be revised time to time as there will be changes and better understanding is obtained on the geologic condition and the seismic activity in the country.

The first seismic zone map was provided in 1962 by the Indian Standards, which was further revised in 1967 and once again in 1970. The map has been last revised in 2002, and it now has seismic zones - II, III, IV and V. The seismic zone I areas were merged with those of seismic zone II in 1970. Seismic Zone Map presents a large scale view of the seismic zones. Hence soil variations and variations in the geology cannot be represented at that scale. Therefore, for major projects, such as large scale dams or a power plant, the seismic danger is investigated specifically in detail for that particular site. For the purposes of urban planning, the area to be urbanised is again zoned further as smaller unit which is known as micro-zoning. By doing so, the local variations in soil profile, geology etc can also be considered.

The important factors that affect the magnitude of earthquake forces are:

\section{a. Seismic Zone Factor, $Z$}

As mentioned earlier, India has been divided into four seismic zones as per IS 1893 (Part 1): 2002. There are different zone factors for different zones.

\section{b. Importance Factor, I}

It relies upon useful utilization of the structures, characterized by hazardous results of its collapse or failure and post-earthquake practical requirements or financial significance. Elevated water tanks are utilized for putting away consumable water and used during crisis for example, putting out fires and are of post earthquake significance. Importance factor is taken as 1.5 for elevated water tank. 


\section{c. Response Reduction Factor, $R$}

It relies on the apparent earthquake hazard and harm caused on the building, described by brittle or ductile displacements. $\mathrm{R}$ values of tanks are not as much as buildings since tanks are less ductile and have low redundancy when compared with other building. For Special Moment Resisting Frame (SMRF), $\mathrm{R}$ value is 2.5 .

\section{d. Structural Response Factor, ( $\mathrm{Sa} / \mathrm{g})$}

It is a component meaning which denotes acceleration response spectrum of the building subjected to soil disturbance due to earthquake and depends on the damping of the structure and natural period of vibration.

\section{e. Objective of the Project}

This paper presents the seismic analysis of an elevated rectangular water tank with mid frame staging and comparison by changing the seismic zone of IS: 1893-2002 (Part-2) and wind speeds for different soil conditions such as hard, medium and soft soil. The elevated rectangular tank has been modelled by using the software ETABS. The water tank is also optimized by N Pandian method.

\section{MODEL DESCRIPTION AND DETAILS}

A. Two Mass Model for Seismic Analysis (IS 1893 Part 22002)

When a tank containing liquid with a free surface is subjected to horizontal earthquake ground motion, tank wall and liquid are subjected to horizontal acceleration. The liquid in the lower part of tank behaves like a mass that is rigidly connected to tank wall. This mass is termed as impulsive liquid mass which accelerates along with the wall and induces impulsive hydrodynamic pressure on tank wall. Liquid mass in the upper part of tank undergoes sloshing effect. This mass is termed as convective liquid mass and it exerts convective hydrodynamic pressure on walls of tank and base. In order to take into account the effect of water on the tank in the analysis, tank can be idealized by an equivalent two mass model, which includes the effect of wall and liquid interaction

Thus, the entire liquid mass gets divided into impulsive mass and convective mass and these two liquid masses are to be suitably represented as hydrodynamic pressure distribution on base of the tank and tank walls in spring mass model system.

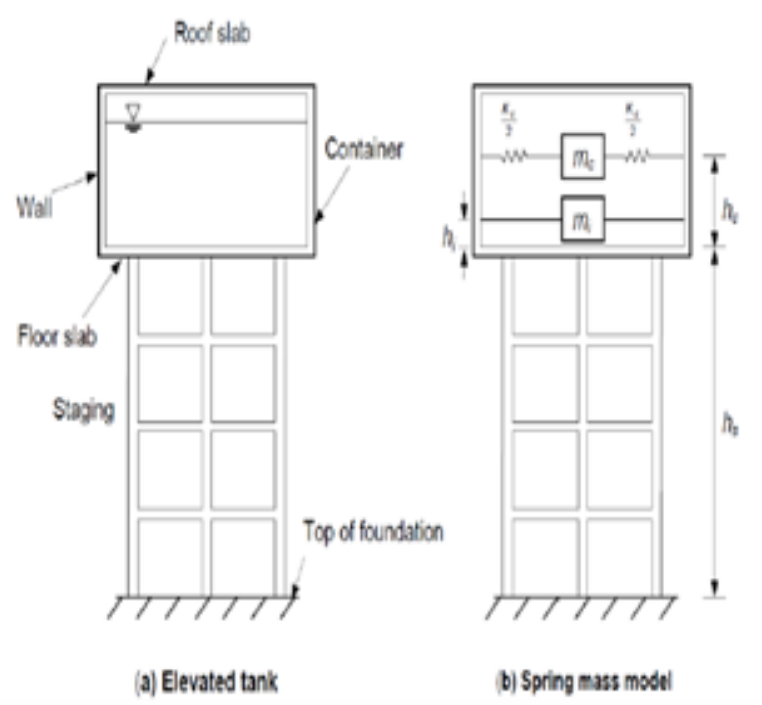

Figure 1: Spring Mass Model Representation

Spring mass model is also called as two mass model as the total liquid mass gets divided into two parts. In two mass model system the two liquid masses are accordingly represented as hydrodynamic pressure distribution on walls of tank and tank base.

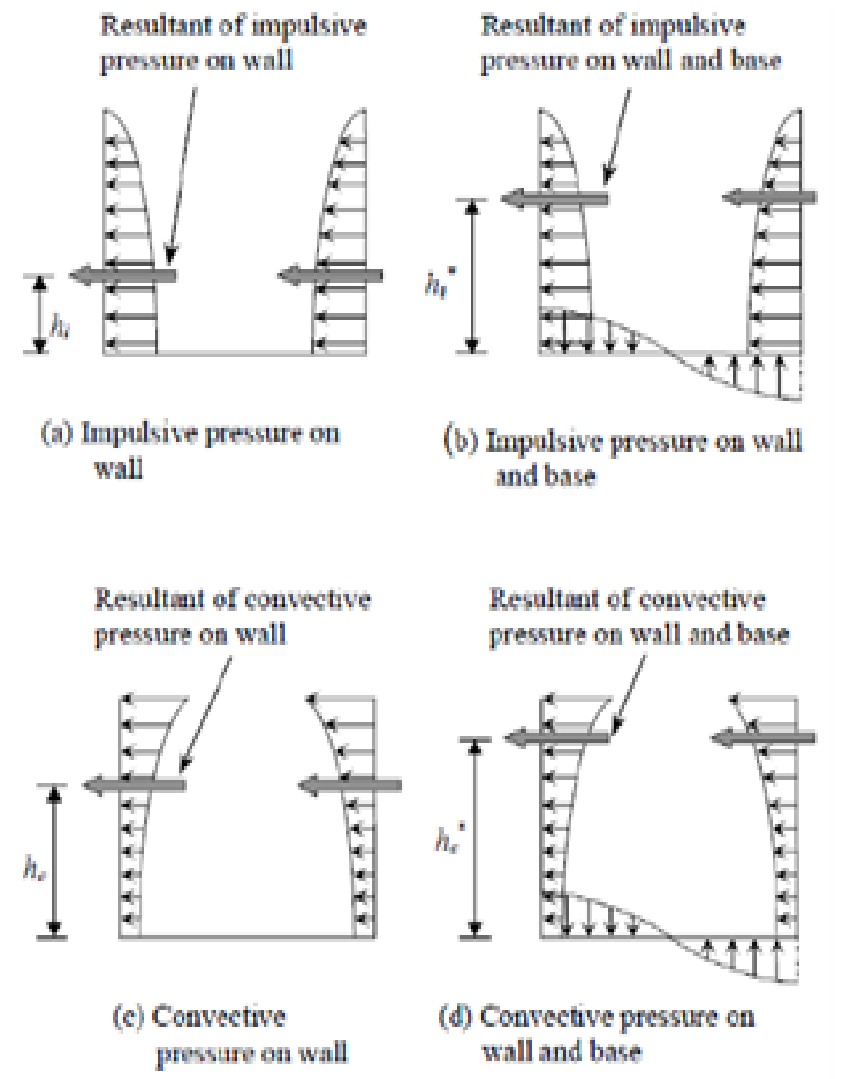

Figure 2: Representation of Impulsive and Convective Pressure on Walls and Base of Tank 


\section{B. Model Description}

Twelve models are prepared for all the four seismic zones and different soil conditions such as hard, medium and soft soil. The data used for the analysis is as follows:

Tank capacity $=1,90,000$ litres

Length $=13.6 \mathrm{~m}$

Width $=5.6 \mathrm{~m}$

Height of tank wall $=2.5 \mathrm{~m}$

Concrete grade $=$ M20 Grade

Steel grade $=\mathrm{Fe} 415$

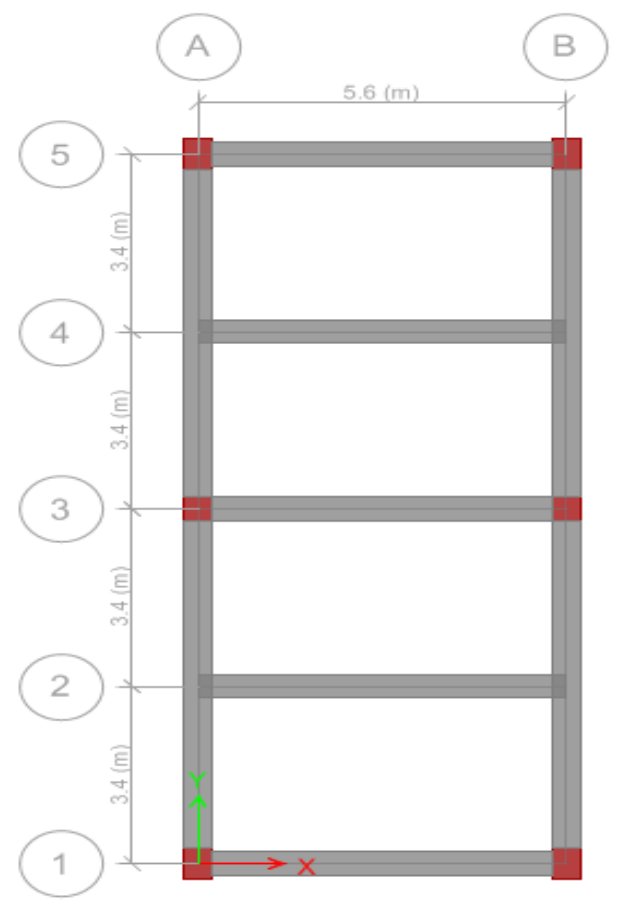

Figure 3: Plan of the Model

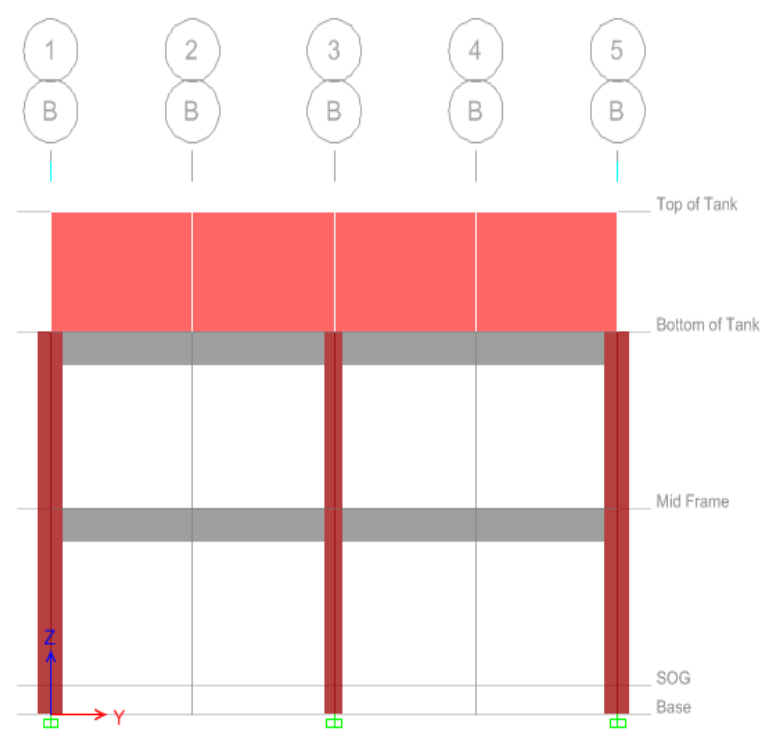

Figure 4: Elevation of the Model
C. Wind load parameters( Ref: IS 875 - Part II):

The wind speeds considered for the analysis in different zones are as follows:

\begin{tabular}{|l|l|l|l|l|}
\hline Zone & II & III & IV & V \\
\hline Wind Speed(m/s) & 33 & 39 & 47 & 50 \\
\hline
\end{tabular}

D. Earthquake Load Parameters :( Ref: IS 1893 - 2002 Part I):

\begin{tabular}{|l|l|l|l|l|}
\hline Zone & II & III & IV & V \\
\hline Zone Factor & 0.1 & 0.2 & 0.25 & 0.4 \\
\hline
\end{tabular}

Importance factor $\mathrm{I}=1.5$

Response Reduction Factor $\mathrm{R}=2.5$

\section{METHODOLOGY}

The elevated water tank is modelled in finite element software ETABS. The walls are modelled as membrane element. Modelling of Beams and Columns are done by considering them as frame element. The tank is modelled for Zone II, Zone III, Zone IV and Zone V with varying basic wind speed for hard, medium and soft soil conditions. Finally parameters such as base shear, displacement, overturning moment for the different zones are compared and presented.

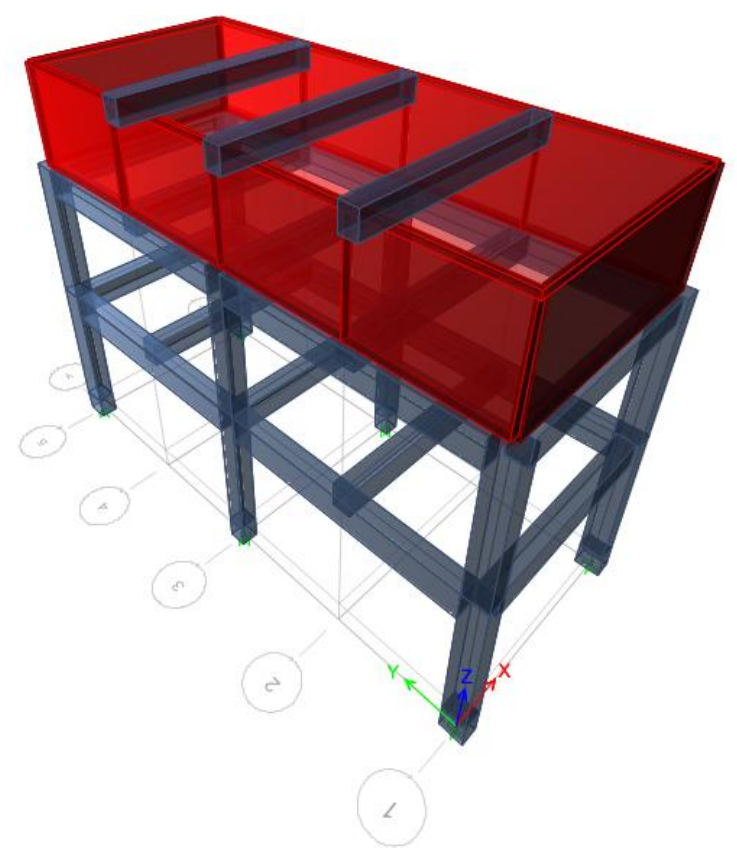

Figure 5: ETABS Model of Rectangular Elevated Water Tank

\section{OPTIMIZATION OF WATER TANK}

Optimization techniques assume an essential part in structural design, the very motive behind which is to locate the most ideal ways so that a designer or the person involved can get greatest advantage from the accessible assets. The essential thought behind natural or backhanded design in engineering is the memory of past encounters, subliminal thought processes, inadequate consistent procedures, irregular determinations or at times unimportant The inadequacies of the roundabout and inconvenient design can be overcome by receiving an optimum system of design. 
The main feature of the optimum design is that it comprises of just reasonable decisions. In settling on a coherent choice, one set out the constraints or requirements and after that minimizes or maximizes the objective function (eg. weight, expenditure or target capacity).

\section{A. Requirements for Structural Design}

The basic and the most important requirement for a structural design to be efficient is that the response of the structure should agree to the various specifications, i.e., the structural design should at least be feasible. Huge amount of designs can be feasible, but the important thing is selection of the best one from these various possible designs. The best design could be chosen based on least weight, lowest cost or highest performance or a combination of these parameters. Several optimization methods give rise to either minimum or maximum but in general give rise to local minimum the most. This depends on the mathematical nature of the constraints and objective function.

\section{B. Methodology}

The mathematical formulas are taken from the $\mathrm{N}$ Pandian method, considering the wall as slab. The constant values for the formulas are taken from $\mathrm{N}$ Pandian principle. The walls of the tank are designed as a simply supported slab and the steel obtained by theoretical calculations are compared with the optimum values.

\section{Design Principles}

The design principles of base slab and side walls as a simply supported slab is consider and discussed below. The long walls in the water tanks are designed as a simply supported slab and the load is taken as triangular water pressure zero at the top and maximum at the base. For members in contact with the liquid (eg. inner faces or roof slab), $25 \mathrm{~mm}$ is the minimum cover to all reinforcement or it can be diameter of the main bar whichever has the highest value. For faces and parts of the structure which aren't in contact with the liquid the cover shall be as for ordinary concrete member.

\section{Loads Considered \\ a. Dead Load}

The dead load in a tank includes the self weight of the structure and all other superimposed dead loads (viz, all permanent constructions and installations including weight of all side slabs).

\section{b. Live Load}

The magnitude of live load to be taken generally depends upon the type of occupancy of the tank. IS 3375 part 4 gives certain minimum values of live loads for specific purpose.

\section{c. Water Pressure}

The water pressure is triangular or uniformly varying load which is zero at the top and maximum at the bottom of the water tank.

\section{E. $\quad$ P Pandian Method}

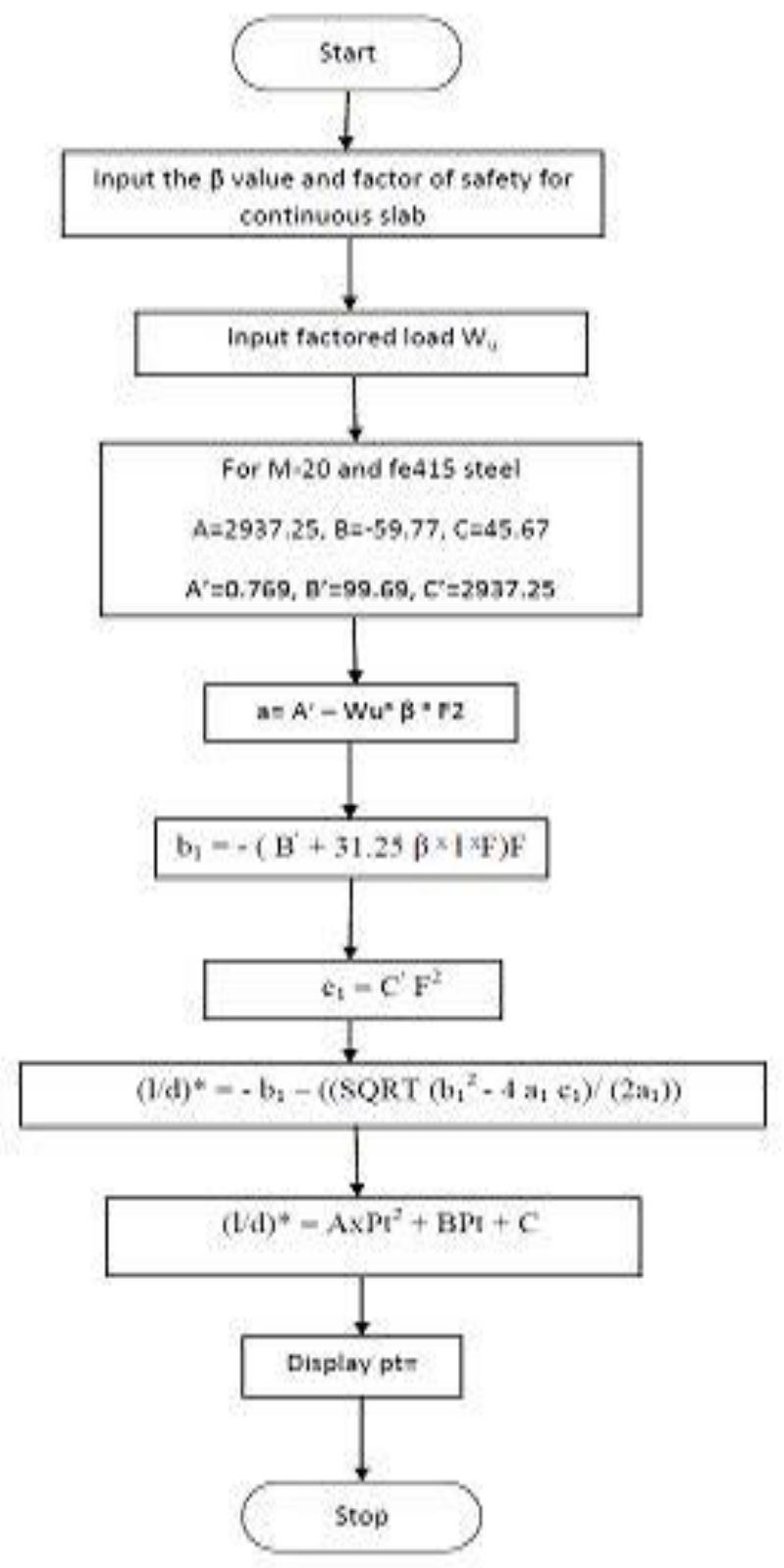

Figure 6: Flow Chart Representing N Pandian Method

Optimum values for the 1.9 lac litre water capacity water tank considered for theoretical formulation are,

$\beta=0.125$

Factor of Safety $=1.5$

For M20 concrete and Fe 415 HYSD bars

$A^{\prime}=0.769$

$\mathrm{B}^{\prime}=99.69$

$C^{\prime}=2973.25$

$\mathrm{A}=30.876$

$\mathrm{B}=-59.77$

$\mathrm{C}=45.67$ 
Step 1:

$$
\begin{aligned}
& \mathrm{a}_{1}=\mathrm{A}^{\prime}-\mathrm{W}_{\mathrm{u}} \times \beta^{\times} \times \mathrm{F}^{2-[8]} \\
& \mathrm{b}_{1}=-\left(\mathrm{B}^{\prime}+31.25 \beta \times 1 \times \mathrm{F}\right) \mathrm{F}^{-[8]} \\
& \mathrm{c}_{1}=\mathrm{C}^{\prime} \mathrm{F}^{2-[8]}
\end{aligned}
$$

Step 2:

$$
(1 / d)^{*}=-b_{1}-\left(\operatorname{SQRT}\left(b_{1}^{2}-4 a_{1} c_{1}\right) /\left(2 a_{1}\right)\right)^{-[8]}
$$

Step 3:

$$
(1 / \mathrm{d})^{*}=\mathrm{APt}^{2}+\mathrm{BPt}+\mathrm{C}^{-[8]}
$$

Optimum solution for the long wall, short wall and base slab of the tank considered:

Table 1: Optimum Solution of Different Components of Tank

\begin{tabular}{|l|l|l|l|l|l|l|}
\hline & \multicolumn{3}{|l|}{ Normal Design } & \multicolumn{2}{l|}{ Optimum Design } \\
\cline { 2 - 7 } & $\begin{array}{l}\text { Long } \\
\text { wall }\end{array}$ & $\begin{array}{l}\text { Short } \\
\text { wall }\end{array}$ & $\begin{array}{l}\text { Base } \\
\text { slab }\end{array}$ & $\begin{array}{l}\text { Long } \\
\text { wall }\end{array}$ & $\begin{array}{l}\text { Short } \\
\text { wall }\end{array}$ & $\begin{array}{l}\text { Base } \\
\text { slab }\end{array}$ \\
\hline $\mathrm{A}_{\mathrm{st}}$ & 2522.4 & 1650.2 & 1923.4 & 1662.5 & 1487.5 & 1662.5 \\
& 0 & 6 & 7 & 0 & 0 & 0 \\
\hline $\mathrm{P}_{\mathrm{t}}$ & 1.44 & 0.94 & 1.10 & 0.95 & 0.85 & 0.95 \\
$\%$
\end{tabular}

\section{RESULTS AND DISCUSSION}

In this paper attempt has been made to study the seismic performance of rectangular elevated water tanks for the following cases:

Case I: Wind speed, $\mathrm{V}_{\mathrm{b}}=33 \mathrm{~m} / \mathrm{s}$, Zone II

Case II: Wind speed, $\mathrm{V}_{\mathrm{b}}=39 \mathrm{~m} / \mathrm{s}$, Zone III

Case III: Wind speed, $\mathrm{V}_{\mathrm{b}}=47 \mathrm{~m} / \mathrm{s}$, Zone IV

Case IV: Wind speed, $\mathrm{V}_{\mathrm{b}}=50 \mathrm{~m} / \mathrm{s}$, Zone $\mathrm{V}$

All the above cases are analysed for Hard, Medium and Soft soil conditions. Hence a total of 12 cases are generated. For all the above mentioned 12 cases, 12 water tank models are generated and the analysis has been performed by using ETABS software. Earthquake analysis is carried out for different soil conditions and different earthquake zones. The main motive of this paper was to study and analyse the effect of seismic forces on reinforced cement concrete elevated rectangular water tank in seismic zones II, III, IV and V for soft, medium and hard soil types.

\section{Base Shear Force}

The Base Shear values are the same for medium and soft soil condition. It varies for hard soil though. The base shear value increases by around 50\% from zone II to zone III, by $25 \%$ from zone III to zone IV and about $60 \%$ from zone IV to zone $\mathrm{V}$ for all the soil conditions. It can be seen that the base shear values are less for hard soil compared to medium and soft soil.
Table 2: Base Shear Values for different Zones and Soil Types

\begin{tabular}{|c|c|c|c|c|c|}
\hline \multirow{2}{*}{ Hard Soil } & Zone & II & III & IV & V \\
\cline { 2 - 6 } & $\begin{array}{c}\text { Base } \\
\text { Shear } \\
(\mathrm{KN})\end{array}$ & 142.18 & 284.39 & 355.48 & 568.72 \\
\hline
\end{tabular}

\begin{tabular}{|c|c|c|c|c|c|}
\hline $\begin{array}{c}\text { Med } \\
\text { Soil }\end{array}$ & $\begin{array}{c}\text { Zone } \\
\text { Base Shear } \\
(\mathrm{kN})\end{array}$ & 172.22 & 344.45 & 430.57 & 688.9 \\
\hline
\end{tabular}

\begin{tabular}{|c|c|c|c|c|c|}
\hline Soft & Zone & II & III & IV & V \\
\cline { 2 - 6 } Soil & Base Shear(kN) & 172.22 & 344.45 & 430.57 & 688.9 \\
\hline
\end{tabular}

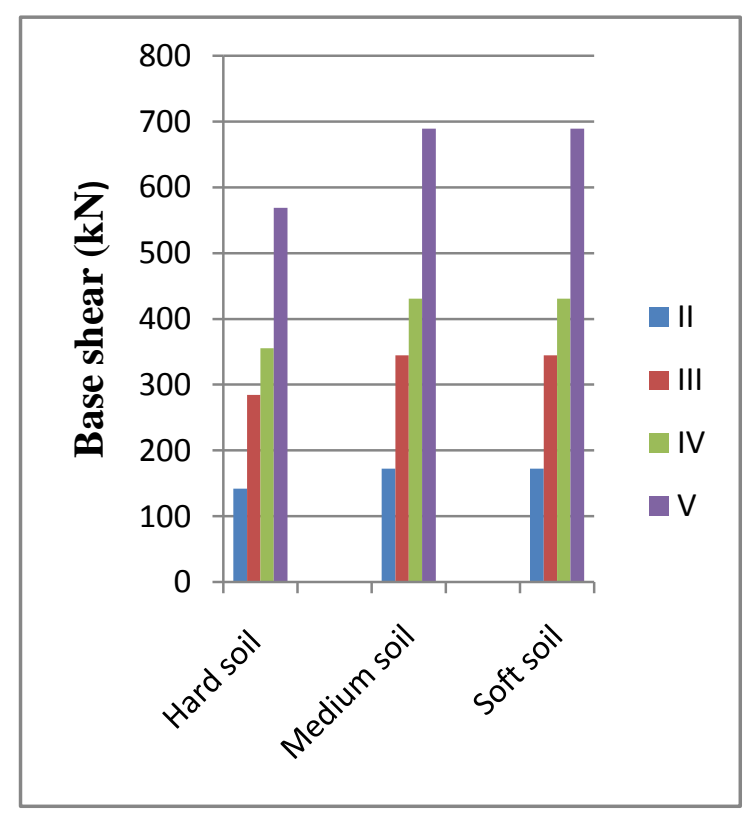

Figure 7: Base Shear Representation of All Zones and Soil Types

\section{Storey Displacements and Drifts}

The storey displacement and drift values for different zones and different soil conditions are shown in the table below. It can be seen that the maximum storey displacement which is at the top of the tank increases with increase in the zone factor and wind speed in each of the soil types. This is because as the wind speed increases the design wind pressure also increases and hence the displacement also increases. The displacement is least for hard soils and is nearly the same for medium and soft soils. Drift is highest at the mid frame of the elevated tank. Though the drift values are nearly equal to zero in all the case, still it can be noticed that the drift is maximum for the tank located in zone $\mathrm{V}$ and is minimum for the tank which is in zone I. Storey drift is the least in hard soil and is the same in case of medium and soft soil. 
Table 3: Storey Displacement Values for Different Zones and Different Soil Type

\begin{tabular}{|c|c|c|c|c|c|}
\hline \multirow{2}{*}{$\begin{array}{l}\text { Soil } \\
\text { type }\end{array}$} & \multicolumn{5}{|l|}{ X-Direction } \\
\hline & Zone & II & III & IV & $\mathrm{V}$ \\
\hline \multirow{2}{*}{ Hard } & Displacement $(\mathrm{mm})$ & 4.40 & 8.70 & 11.0 & 17.5 \\
\hline & Drift(unitless) & $640 \mathrm{E}-06$ & $1.28 \mathrm{E}-03$ & $1.6 \mathrm{E}-03$ & $2.58 \mathrm{E}-03$ \\
\hline \multirow{2}{*}{ Medium } & Displacement $(\mathrm{mm})$ & 5.30 & 10.70 & 13.31 & 21.30 \\
\hline & Drift(unitless) & $780 \mathrm{E}-06$ & $1.55 \mathrm{E}-03$ & $1.97 \mathrm{E}-03$ & $3.10 \mathrm{E}-03$ \\
\hline \multirow{2}{*}{ Soft } & Displacement $(\mathrm{mm})$ & 5.37 & 10.72 & 13.40 & 21.30 \\
\hline & Drift(unitless) & $780 \mathrm{E}-06$ & $1.10 \mathrm{E}-03$ & $1.95 \mathrm{E}-03$ & $3.12 \mathrm{E}-03$ \\
\hline
\end{tabular}

\begin{tabular}{|c|c|c|c|c|c|}
\hline \multirow{2}{*}{$\begin{array}{l}\text { Soil } \\
\text { type }\end{array}$} & \multicolumn{5}{|l|}{$Y$-Direction } \\
\hline & Zone & II & III & $I V$ & V \\
\hline \multirow{2}{*}{ Hard } & Displacement $(\mathrm{mm})$ & 3.84 & 7.22 & 9.10 & 14.63 \\
\hline & Drift(unitless) & $550 \mathrm{E}-06$ & $1.09 \mathrm{E}-03$ & $1.31 \mathrm{E}-03$ & $2.18 \mathrm{E}-03$ \\
\hline \multirow{2}{*}{ Medium } & Displacement $(\mathrm{mm})$ & 3.72 & 7.40 & 9.30 & 15.00 \\
\hline & Drift(unitless) & $570 \mathrm{E}-06$ & $1.10 \mathrm{E}-03$ & $1.40 \mathrm{E}-03$ & $2.25 \mathrm{E}-03$ \\
\hline \multirow{2}{*}{ Soft } & Displacement $(\mathrm{mm})$ & 3.75 & 7.50 & 9.35 & 15.00 \\
\hline & Drift(unitless) & $570 \mathrm{E}-06$ & $1.55 \mathrm{E}-03$ & $1.40 \mathrm{E}-03$ & $2.25 \mathrm{E}-03$ \\
\hline
\end{tabular}

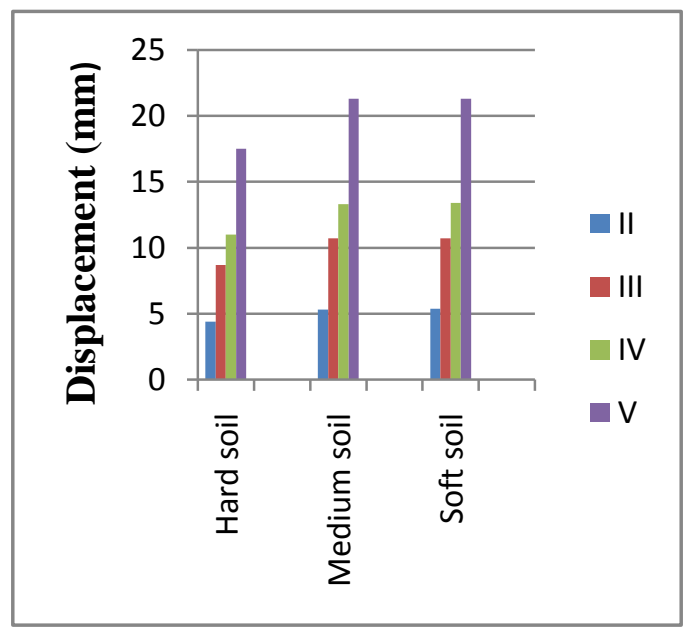

Figure 8: Displacement Due to Earthquake Force along X-Direction

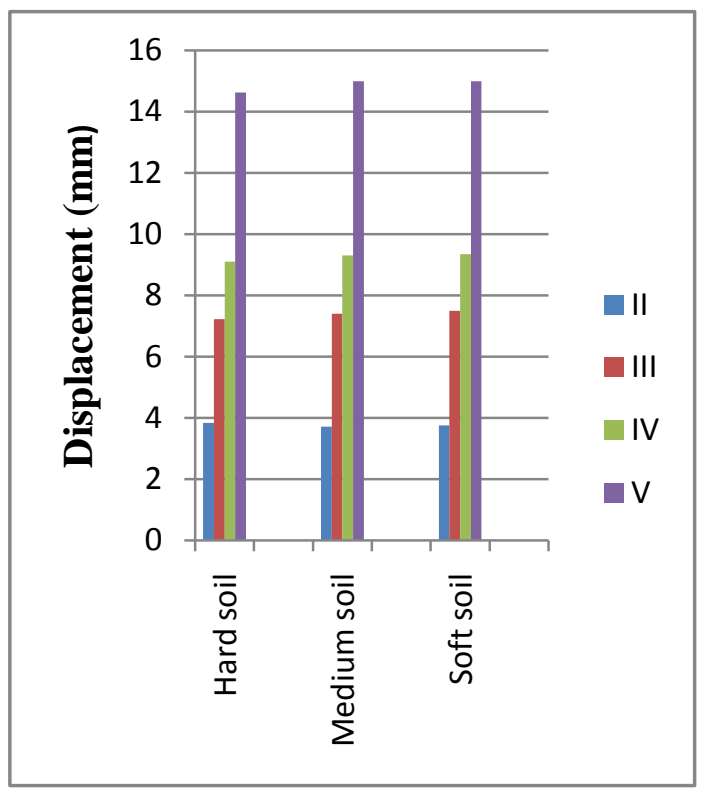

Figure 9: Displacement Due to Earthquake Force along Y- Direction

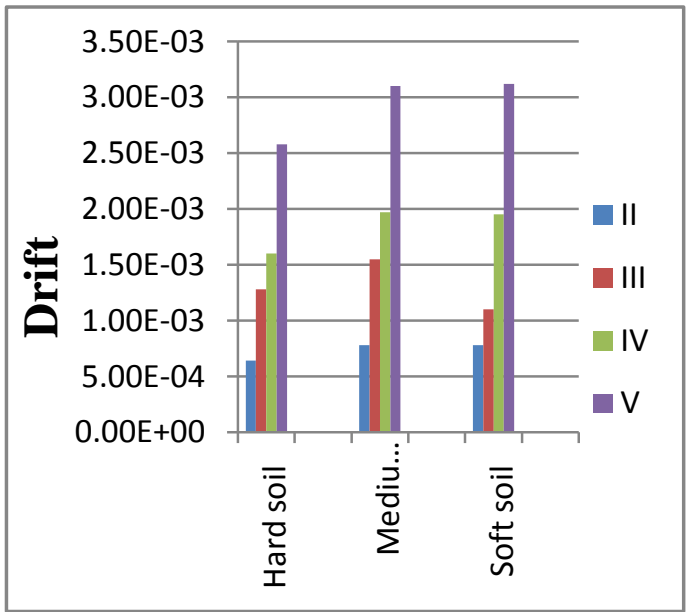

Figure 10: Drift due to Earthquake Force along X-Direction

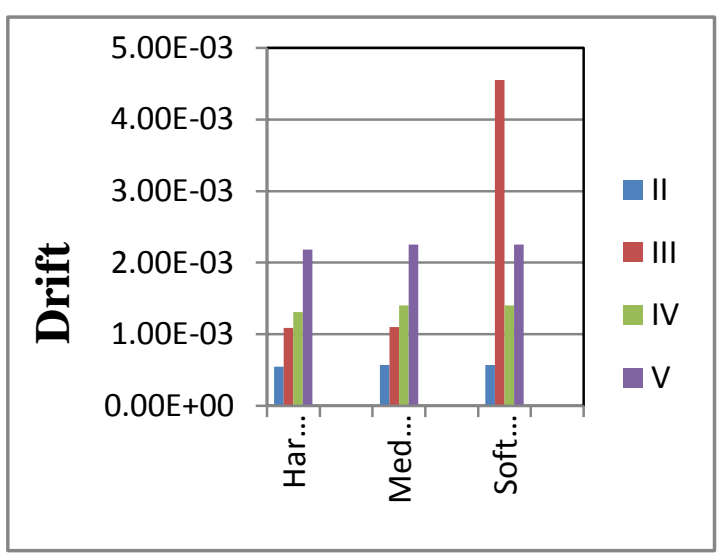

Figure 11: Drift Due to Earthquake Force along X-Direction

\section{Overturning Moments}

Overturning moment is the moment which is generated due to the pressure of the soil and which overcomes the stability of the structure and causes its failure. Here the overturning moment due to earthquake load has been represented. It is different for different heights and is maximum at the base of the structure. 
Overturning moment is highest in case of soft soil and is least in that of hard soil. Among all the zones, for all soil conditions, maximum value is for zone $\mathrm{V}$ and the least value is for zone II.

Table 4: Overturning moments for different zones and different soil type

\begin{tabular}{|c|c|c|c|c|c|c|c|c|c|}
\hline \multirow[t]{2}{*}{ Soil Type } & & \multicolumn{4}{|c|}{$X$-Direction } & \multicolumn{4}{|c|}{$Y$-Direction } \\
\hline & Zone & $I I$ & III & $I V$ & V & $I I$ & III & $I V$ & $V$ \\
\hline Hard soil & \multirow{3}{*}{$\begin{array}{l}\text { Overturning moment at base } \\
(\mathrm{kN}-\mathrm{m})\end{array}$} & -1.26 & -2.52 & -3.18 & -5.00 & 1.50 & 3.00 & 3.70 & 6.00 \\
\hline Med soil & & -1.52 & -3.00 & -3.80 & -6.15 & 1.52 & 3.10 & 3.85 & 6.20 \\
\hline Soft soil & & -1.54 & -3.02 & -3.80 & -6.10 & 1.52 & 3.05 & 3.82 & 6.10 \\
\hline
\end{tabular}

\section{Optimization Results}

Values of steel obtained from theoretical formulation and the optimum values obtained by $\mathrm{N}$ Pandian method are shown in the table below:

Table 5: Comparison of Normal and Optimum Design Values

\begin{tabular}{|l|l|l|l|l|l|l|}
\hline \multirow{2}{*}{} & \multicolumn{4}{|l|}{ Normal Design } & \multicolumn{3}{l|}{ Optimum Design } \\
\cline { 2 - 7 } & $\begin{array}{l}\text { Long } \\
\text { wall }\end{array}$ & $\begin{array}{l}\text { Short } \\
\text { wall }\end{array}$ & $\begin{array}{l}\text { Base } \\
\text { slab }\end{array}$ & $\begin{array}{l}\text { Long } \\
\text { wall }\end{array}$ & $\begin{array}{l}\text { Short } \\
\text { wall }\end{array}$ & $\begin{array}{l}\text { Base } \\
\text { slab }\end{array}$ \\
\hline $\mathrm{A}_{\mathrm{st}}$ & 2522.40 & 1650.26 & 1923.47 & 1662.50 & 1487.50 & 1662.50 \\
\hline $\mathrm{P}_{\mathrm{t}} \%$ & 1.44 & 0.94 & 1.10 & 0.95 & 0.85 & 0.95 \\
\hline
\end{tabular}

It can be seen that the area of steel and percentage of steel values got from optimum design by $\mathrm{N}$ Pandian method is less than the values got from the normal design procedure. Hence it is a suitable technique for optimum design of elements and it makes the tank more economical.

\section{SUMMARY AND CONCLUSION}

\section{A. Summary}

In this paper, an effort is put to study the seismic behaviour of an elevated rectangular water tank for different seismic zones of India and for different soilconditions. It is studied for various parameters like base shear, overturning moments, displacements, storey drifts for all the seismic zones and presented for hard, medium and soft soil. The tank is then optimized by using $\mathrm{N}$ Pandian method of optimization. The theoretical values and the optimum values are compared and presented

\section{B. Conclusion}

Some of the important conclusions that can be drawn from the present study:

1. Elevated rectangular water tanks must be designed as two mass spring model as the effect of hydrodynamic pressure is very important and must be considered.

2. The displacement is more in soft soils and is the least in hard soils. The displacement value is maximum when the tank is located in zone $\mathrm{V}$ in case of soil types.

3. Drift is seen in all the storeys of the tank but is maximum for mid frame. It is nearly equal to zero for all the seismic zones and soil conditions.

4. Base shear values are the same for both medium and soft soils. It is maximum for these soils and is least for hard soil

5. The overturning moments is more in case of soft soil and has the maximum value when the tank is located in zone $\mathrm{V}$. The overturning moments increase as the seismic zoning increases.
6. The percentage of steel values is optimum and less when N Pandian method is used and the design can be made more economical.

7. Present study will be of great use to Civil Engineers to understand the performance of rectangular elevated water tank located in different seismic zones subjected to different wind speeds and various soil conditions and also to understand the effect of earthquake zones of India and soil conditions on earthquake forces.

\section{REFERENCES}

[1]. D.V.S. Uma Maheswari and B. Sravani, "Performance of Elevated Circular Water Tank in Different Seismic Zones", International Journal for Technological Research In Engineering, Vol 3, Pp. 932-937, 2016.

[2]. S. Hirde, M.A. Bajare and M. Hedaoo, "Seismic performance of elevated water tanks", International Journal of Advanced Engineering Research and Studies, Vol. 1, No. 1, Pp. 78-87, 2011.

[3]. H. Sezen, R. Livaoglu and A. Dogangun, "Dynamic analysis and seismic performance evaluation of above-ground liquid-containing tanks", Engineering Structures, Vol. 30, No. 3, Pp. 794-803, 2008.

[4]. IITK- GSDMA, "Guidelines for Seismic Design of Liquid Storage Tanks", NICEE Publications, 2007.

[5]. M. Moslemi, M.R. Kianoush and W. Pogorzelski, "Seismic response of liquid-filled elevated tanks”, ELSEVIER Journal, Pp. 2075-2083, 2011.

[6]. N. Krishnaraju, "Advanced Reinforced concrete Design", CBS publisher and distributors, New Delhi, 2009.

[7]. N.R. Patil and R.S. Talikoti, "Seismic Behaviour of Elevated Water Tank", International Journal of Research in Engineering and Technology, Vol. 4, 2015.

[8]. N.J. Singh and M. Ishtiyaque, "Design Analysis \&Comparison of Intze Type Water Tank for Different Wind Speed and Seismic Zones as per Indian Codes", International Journal of Research in Engineering and Technology, Vol. 4, 2015, Pp. 291-300.

[9]. R. Livaoğlu and A. Doğangün, "Dynamic Behavior and Seismic Performance of Elevated Tanks due to Ground Types Defined In Ec-8 and Tec-06 First European Conference on Earthquake Engineering and Seismology", 2006.

[10]. S. Farrukh Anwar and A.K. Asthana, "Evaluation of Seismic Design Forces of Indian Building Code", International Journal of Engineering Research \& Technology, Vol. 2, Pp.1325-1330, 2013.

[11]. V. Veeresh, Dr.S.B. Vankudre and P. Prabhavati, "Optimization of Water Tank", The International Journal Of Science \&Technoledge, Vol. 2, Pp. 44-53, 2014. 